\title{
Stigmata in cutaneous leishmaniasis: Historical and new evidence-based concepts
}

\author{
Mohamed Ahmed Al-Kamel
}

${ }^{1}$ Chair, Department of Dermatology, Regional Leishmaniasis Control Center (RLCC), Sana'a University Hospital, Sana'a, Yemen

Corresponding author: Dr. Mohamed Ahmed Al-Kamel, E-mail: dralkamel@hotmail.com

\begin{abstract}
This report is a part of many articles and studies published by the Regional Leishmaniasis Control Center (RLCC). Willing that this review might enrich understanding of the global epidemiological profile of CL, the author relied on research evidence, his experience and a social survey to highlight historical and current concepts of cutaneous leishmaniasis (CL) as a globally most prevalent and highly stigmatizing form of leishmaniasis disease, introduce new ideologies upon CL-related stigmata, review the most common determinants and implications of CL stigmata; and report a short survey illustrating stigmata experience among some affected patients from Yemen. He also reviewed a successful community-led action to reduce the burden of CL and its related stigmata in Yemen.
\end{abstract}

Key words: Cutaneous; Leishmaniasis; Stigma; Stigmata; Concepts; Yemen

Abbreviations: ELYP, Eradication of Leishmaniasis from yemen Project; RLCC, Regional Leishmaniasis Control Center; CL, Cutaneous leishmaniasis; MCL, Mucocutaneous leishmaniasis; VL, Visceral leishmaniasis; DCL, Disseminated cutaneous leishmaniasis; CLS, Cutaneous leishmaniasis stigma; CLSS, Cutaneous leishmaniasis social stigma; CLAS, Cutaneous leishmaniasis aesthetic stigma; CLPS, Cutaneous leishmaniasis psychological stigma; NTD, Neglected tropical diseases; WHO, World Health Organization; ISD, International Society of Dermatology; AAD, American academy of Dermatology; ILDS, International League of Dermatological Societies

\section{INTRODUCTION}

Stigma related to chronic health conditions, particularly neglected tropical diseases (NTD) is a global phenomenon and stealth weapon that results in severe unwanted consequences, and its related concepts have become an increasingly important topic for health sciences.

Although leishmaniasis disease-linked lifelong stigma have been reported from several countries and the WHO has recently highlighted its severity, dermatology literatures characterizing the epidemiology of leishmaniasis have almost not readily accounted for the ideologies and hidden burden of its stigma $[1,2]$.

Molly's concluded with a proposed origin and evolution of human Leishmaniasis being initially linked to the origin of man in Africa (since the beginning of life on Earth) and then following these organisms throughout the Paleoarctic. It has been historically portrayed in ceramics, figures, papyrus and statues [3-5].

Leishmaniasis, a chronic infectious but non-contagious disease, is widespread in tropical and subtropical areas, caused by Leishmania parasites, transmitted by bites of infected female phlebotomine sandflies and its primary hosts are vertebrates (most likely humans, canids, rodents and hyraxes). The human leishmaniasis particularly affects the poor [1].

As per previously published recommendation by the author and according to several dermatology literatures, leishmaniasis has been simply classified into two broad clinical types: (1) stigmatizing cutaneous leishmaniasis 
(CL); (2) the lethal (if untreated) visceral leishmaniasis (VL) $[1,4,5]$.

\section{Stigma - Historical Background}

The Greeks first used the term 'stigma' to describe a mark made through branding to designate a person of undesirable moral character. In the nineteenth century, there were a striking analogy between skin disease and poverty, therefore stigma connected with skin disorders might have gained greater cultural value. In 1895, French sociologist Émile Durkheim was the first to explore stigma as a "social phenomenon". In 1963, Canadian-American Erving Goffman [1], one of the most influential sociologists of the twentieth century, introduced stigma into the psychological literature as "the phenomenon whereby an individual with an attribute which is deeply discredited by his/her society is rejected as a result of the attribute; stigma is a process by which the reaction of others spoils normal identity." Stigmatized people are those that do not have full social acceptance and are constantly striving to adjust their social identities. He identified three types of stigma: stigma of character traits, physical stigma and stigma of group identity (tribal stigma). Merriam-Webster simply defines stigma as "a set of negative and often unfair beliefs that a society or group of people have about something." [6,7]

\section{Cutaneous Leishmaniasis - Historical and Current Concepts}

First description of conspicuous lesions similar to current cutaneous leishmaniasis (CL) has been reported in texts dating back to 2500-1500 BC [1]. In the Americas, evidence of the cutaneous form of the disease in Peru, Colombia and Ecuador appears in pottery depicting skin lesions and deformed faces dating back to AD 400 to AD 900. In the $10^{\text {th }}$ century, Arab physicians provided more descriptions about the disease $[8,9]$.

Clinically, CL is considered one of the most serious skin diseases in developing countries. The World Health Organization (WHO, 2004) has acknowledged it as a severely neglected 'Category l' disease, which covers emerging or uncontrolled diseases. In 2013, the global mean age-standardized DALYs for CL was 0.58 per 100,000 people [3].

CL is a spectral and extremely stigmatizing disease that is often compared with leprosy, and predominantly affects face and other visible parts of the body. It usually presents with a single or multiple nodules, ulcers, or plaques on skin (cutaneous leishmaniasis; CL), mucous membranes (mucosal leishmaniasis; ML), or both, skin and mucous membranes (mucocutaneous leishmaniasis; MCL).

Although, some CL lesions heal spontaneously leaving ugly life-long scars, the majority of lesions are non-healing or chronic with sequels leading to disfigurement or mutilation with severe social and economic consequences [10].

CL may progress to MCL when dissemination by hematogenic or lymphatic route occurs, and most discussions of the disease have considered MCL as a severe form of CL. Untreated MCL lesions often lead to extensive, disfiguring destruction of mucous tissues of the mouth, pharynx, larynx, nose, or eyes, as well as other affected parts of the skin, causing extreme aesthetic alteration, serious disability and may end with death due to chronicity and respiratory complications $[4,11]$.

\section{Synonyms}

As a mysterious disease with persistent prevalence, CL lesions have been cited with various popular names that differ from a region to region, such as; "Balkh" and "Kandehar sore" in Afghanistan; "Baghdad boil" and "Basra button" in Iraq; "Biskra boil" or "bouton de Biskra" in Algeria; "Aleppo evil" in Syria; "badah", "Ofiah" and "atharah" in Yemen; "little sister" in Saudi Arabia (the South); "Jericho boil" in Jordan; "Pendeh sore" in central Asia; "Delhi boil" in India; "Ashkhabad sore" in Tukmenistan; "godovik" in Russia; "caneotica" in China; "salek" in Iran; "angry ulcer" in the Pacific; "bouton de Crète" in Greek island; "mountain leprosy" in Amazon region; "chiclero's ulcer" in Mexico and Ecuador; etc.

Although, some of these vernacular names suggest links to the lesion' morphology, disease course, geographic location, cultural beliefs (mythology), other terms refer to CL accompanying stigma. As an example, all identified local terms for CL in Yemen actually mean 'stigma' and refer to both aesthetic and social stigmata (Al-Kamel MA, 2016); "Badah" means "apparent", "Atharah" means "trace" and "Ofiah" means "ugly" [5]

\section{Cutaneous Leishmaniasis Stigma (CLS)}

Stigmatization is the hidden and often neglected manifestations of the visible features of CL. Evidence shows that CLS is developed primarily from the extreme 
aesthetic and functional alteration that disfigurement, ulceration, scarring and deformities may cause, making affected people look different from others.

\section{CLASSIFICATION OF CUTANEOUS LEISHMANIASIS-RELATED STIGMATA}

As per author's perspective, stigmata that potentially apply to CL has been classified into three main types:

\section{Social Stigma (CLSS)}

CLSS is that has been referred to by most the literatures discussing stigmatization in CL and some chronic skin conditions, such as leprosy.

Simply, CLSS is the negative and often unfair beliefs that a society have about patient bearing CL. The concept of social stigma has been classified into [2]: (1) enacted stigma, when patients are confronted with overt acts of discrimination; (2) perceived stigma, when patients fear encountering overt or enacted stigma; (3) internalized stigma, when the social stigma is internalized or accepted by those at whom it is targeted.

In addition to CLSS, the author has identified and defined two more types of CL-related stigmata that he has previously discussed (Al-Kamel, 2015). CL also causes important social and psychological stigma (WHO, 2007) [12].

\section{Aesthetic Stigma (CLAS)}

The author has defined CLAS as a sense of a bodily image dissatisfaction and how aesthetic the CL active lesions, scars, deformities and disabilities look like. CLAS is not necessarily associated with social discrimination or individual isolation. Subsequently, CLAS might be classified into; (1) individual (perceived) CLAS and (2) social (enacted) CLAS.

Because of sandfly vector exposure, most leishmaniasis lesions occur on prominent parts of the body such as mouth, nose, eyes, ears and hands, and thus resulting with a sort aesthetic stigmata that make CL different from all other comparable tropical skin diseases, such as prosy. Evidence showed that patients with active lesions or healed scars showed increased rates of body satisfaction impairment $[13,14]$.

\section{Psychological Stigma (CLPS)}

CL might profoundly influences patient's personality and psychological well-being, constituting a more destructive power inside CL-affected individuals.

CLPS is the deepest dimension of the prominent CL lesions. The authors has defined CLPS as the deep pain or the psychological stress the infected patient feels as a result of CL-related fears, social stigma and aesthetic stigma.

"The deep pain the leishmaniasis-related-stigma insert inside the affected women is the most destructive power in their social lives [15]."

\section{GLOBAL BURDEN}

A severe stigma associated with CL, has been reported $^{1}$. It is a global phenomenon of an important consideration $[13,16]$.

In Afghanistan that has had the highest incidence of cutaneous leishmaniasis in the world, it was reported that severe stigma and trauma are associated with CL among all age groups, particularly in children and women [17].

In Yemen, women with CL often present late and experience not only physical deformities and the risk of death, but also the painful stigma and its consequences, a similar situations to that of Leprosy, decades ago. [15 ].

In Ecuador, women from leishmaniasis-endemic areas of NW Ecuador appeared to be more aware of CL and scars because of its associating stigmatization [18].

In Pakistan, "this is not me," a woman said when she explained her encounter with CL related stigma [13].

However, literatures measuring the stigmata arising from CL in some endemic geographical areas in Asia, Africa, South America and Europe have not existed [19].

\section{DETERMINANTS}

All the physical and organic precipitating factors related to the host, vector, reservoir and environment that may influence the morbidity of CL as a physical illness, might also influence the severity of stigmata related to the disease as a stigmatizing agent. Hereafter, determinant factors directly linked to the stigmatization as a moral challenge. 


\section{Personal Determinants}

Disfiguring lesions' attitude (location, severity, visibility and chronicity)

CL scars leave a very strong stigmatizing impact as they last for years. CL disfiguring nodular lesions resemble those of lepromatous leprosy, and patients with disseminated cutaneous leishmaniasis (DCL) usually suffer stigma similar to that associated with leprosy ${ }^{[2]}$. Mucosal lesions are more stigmatizing than cutaneous lesions, active lesions than residual scars, DCL more than individual lesions and those on the prominent features more than those on the hidden parts are.

\section{Physical disabilities}

Some CL forms are chronic with sequels leading to severe disabilities or mutilation with severe social, aesthetic and psychological stigmata.

\section{Gender and age}

Yanik et al. (2004) reported that younger generations affected by CL showed less acceptance of stigma than older adults did [20]. Although, stigmatization occurs in all age and sex groups, its effects are greater in female than male patients are [15].

\section{Morality and psychological wellbeing}

In relation to CL stigma, many suicides or attempts have been recorded [21].

\section{Fearfulness and misconceptions}

Unreasonable fears of infecting others, carcinogenesis and death are not uncommon feelings that could exacerbate CL-related stigmata. Moreover, fears from antileishmanial drugs-associated complications or from social stigmatization beyond exposure and diagnosis, were reported to the author, may prevent patient from seeking medical assistance, make barriers to recovery, and thus directly aggravate CLS. The same outcomes may accompany the false belief that leishmaniasis is of little health importance.

\section{Socio and Geopolitical Determinants}

\section{Sociocultural attitudes}

Magnitude and consequences of CLS vary across societies, respecting several dimensions, such as civilizational, religious and cultural peculiarities. In spite it is well documented that CL stigmatized women are often put on the edges of society and been not eligible for marriage or work in some societies, such as Afghanistan and Yemen, it is likely true in other countries with such conservative societies. On the contrary, S. Ramdas et al. concluded that CL is not generally a stigmatized disease in Suriname (though this is not to deny that stigmatization may occur occasionally) [3].

\section{Mythology}

Myths and often mistaken beliefs, such as "the disease is directly contagious or by sharing meals and household goods", "leishmaniasis is necessarily concomitant with AIDS" and "it is a Divine punishment" are still having an overwhelming impact in some traditional societies with an extreme negative impacts especially on children, as they are prevented from attending school, stigmatized in their communities, and families have been documented to isolate their children from siblings to stop further spread of the infection. Another example, Chayahuitas, a community in the Peruvian Amazon, believe that CL patient has a worm in the nasal cavity that nibbles away at night at the rim of the nostrils and ears [22,23].

\section{Economic context}

Because, leishmaniasis is strongly linked with poverty, scars are considered a mark of low social status carrying with them a social stigma.

\section{Population mobility}

Migration and displacement are important factor in the disease and its related stigmata transmission. People with CL have been victimized as individuals and even in groups, for example, refugees from Afghanistan are identified by their "trademark" scars left behind by CL disease [14].

\section{IMPLICATIONS}

CL not only affects the physical well-being of the infected individual, but also its related stigmata impose what has been termed a "hidden burden" and often affect their psychological, social and economic well-beings.

\section{Implications Upon Individual Context}

CL-related stigmata often lead to a high social burden and marginalization. Unaffected people tend to isolate affected, parents isolate their affected children from others in the family, women are often separated from their children during the disease by their family and not allowed to breast-feed, and younger women often experience difficulties in marriage $[3,16,24]$. 
Evidence showed that CLS might affect the behavior of those who are stigmatized, mould one's personality, shape their emotions and beliefs and completely change one's perception of self, especially for children and women [25]. CL stigmatized patients showed body satisfaction impairment, increased rates of depression and anxiety and even suicidal tendency, with a larger decrement in their quality of life. This may predispose to further physical health deterioration and severe psychiatric morbidity $[13,15,22]$.

In certain societies, CL stigma may also influence individuals' ability for education and employment. Girls and women who became lonely on the grounds of leishmaniasis usually face destitution. Therefore, CL stigma kills its victim socially and literally $[13,26]$.

\section{Implications Upon Social Context}

The social implication of CLS is much more distressing to patients with CL than the disease individual effects. Thus affecting their community interaction, social relationships and friendships. Their families may experience reduced educational opportunities that may contribute to higher illiteracy rates and further inequities between those affected and those who are not. An example, about 2,000 students in different parts of Badakhshan (Afghanistan), most of them girls, have reportedly been absent since the leishmaniasis outbreak started, provincial officials said.

CLS also may influences labor market, reduces work capacity and national income. For example, $77 \%$ of men in Ecuador believe that CL diminishes their ability to work [22].

\section{Implications Upon Public Health}

CLS may hinder treatment seeking through fear or shame to be seen in public places or because of social exclusion that may result in the disease getting worse, increase transmission and make it difficult to trace patients [27].

\section{SITUATION IN YEMEN: IMAGE, ACTION AND SURVEY}

Yemen republic is high endemic for the neglected, deadly flesh-eating leishmaniasis disease that affects predominantly poor rural women and children [13]; it is one of the nine countries that had significantly greater DALYs from CL than the mean [27].
Literatures conducted at the Regional Leishmaniasis Control Center (RLCC), Yemen, concluded that: Leishmaniasis is the most common parasitic infestation and the first most prevalent infectious disease in some regions; Mutilating MCL is the most prevalent form (Fig. 1); Stigma is synonymous with CL; Women with leishmaniasis often present late and experience not only physical deformities and the risk of death, but also the painful stigma of the disease and its consequences, a similar situation to that of leprosy decades ago $[5,15,28]$.

\section{RLCC and ELYP - Community-led Actions}

Regional Leishmaniasis Control Center (RLCC), a charitable non-governmental organization that currently involve 4 regional centers and more than 100 volunteers, was founded during April 2013 in collaboration with the American Academy of Dermatology (AAD) and the International Society of Dermatology (ISD). RLCC was established as the first stage of the ISD-sponsored community dermatology project Eradication of Leishmaniasis from Yemen Project (ELYP) to execute ELYP's community educational, surveillance, detection, treatment, control and research programs and campaigns (Fig. 2). ELYP had took place in January 2013 by the ISD member Dr. Mohamed Ahmed Al-Kamel to confront the dire need for action to implement effective leishmaniasis surveillance and control $[15,29]$.

As an outcome, the project ELYP has achieved spectacular success and received worldwide critical acclaim. It made a big difference in the leishmaniasis

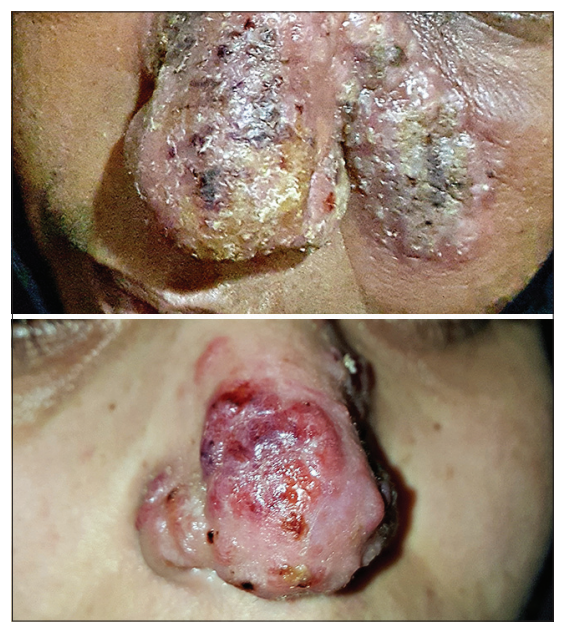

Figure 1: Socially, aesthetically and psychologically stigmatizing MCL lesions affecting two female interviewees at the Regional Leishmaniasis Control Center office in Sana'a, Yemen. 


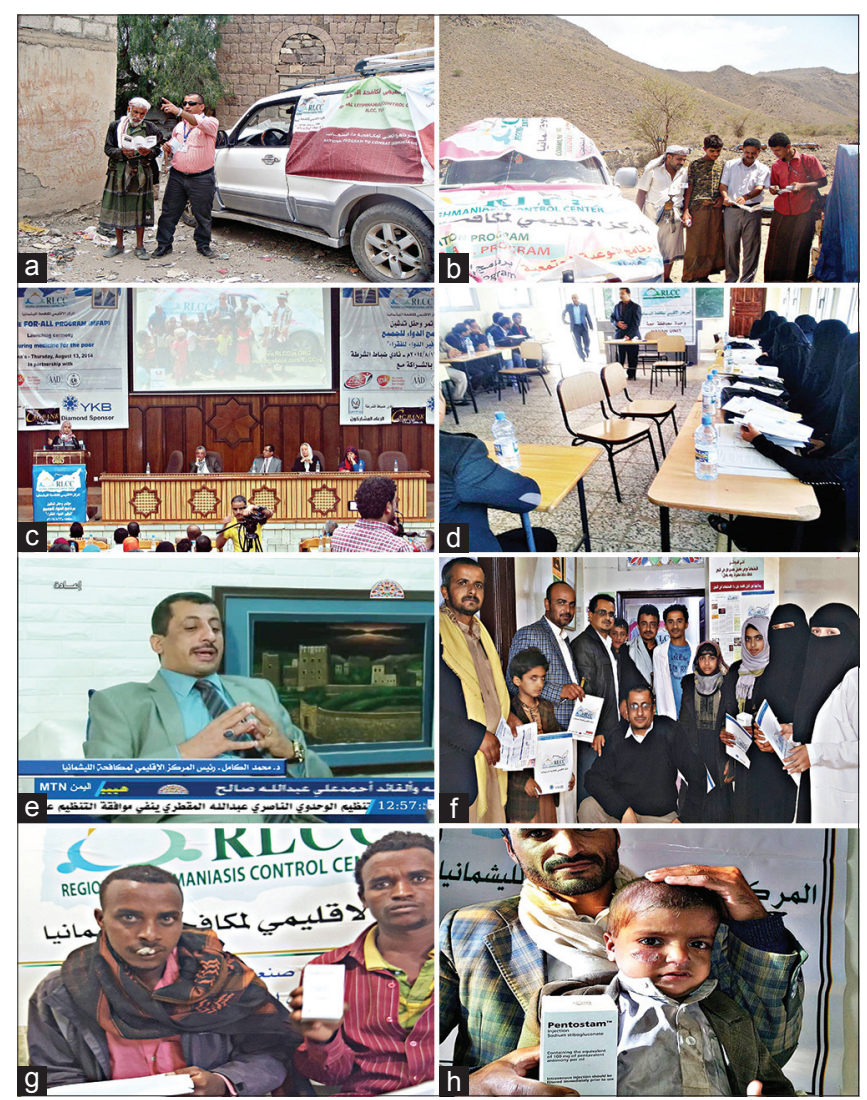

Figure 2: Regional Leishmaniasis Control Center's educational and treatment campaigns to reduce the burden of CL stigmata in Yemen through remote field campaigns ( $a$ and $b$ ), congresses (c), workshops (d), mass media (e), outpatient clinics ( $f$ ), and free medicine donation ( $g$ and $h$ ).

situation in Yemen, addressed its magnitude, eradicated it from some areas, dealt with and improved its alarming prevalence among children and women who are the neglected and highest risk groups, solved some issues associated with poor access to proper drugs and significantly raised community awareness of the disease that was near to zero among most community sectors. Medicine donation through Medicine-For-All Program has enabled patients with leishmaniasis to freely receive medicine they otherwise would not have been able to afford, reduced their mortality and morbidity and minimized the extensive impact leishmaniasis stigmata have on their lives. In addition to those sensible achievements, ELYP has attracted local and global attention to these problematic issues [13].

\section{SOCIAL SURVEY}

\section{Objective}

To screen, assess and measure the existence and extent of the above mentioned types, determinantes and implications of Cl-related stigmata (CLS) among
Yemeni patients population and their relatives, the author concurrently conducted this short social survey at the Regional Leishmaniasis Control Center (RLCC) clinics in Sana'a (the capital city) and Radaa (an endemic district of Al-Baydaa governorate). He's willing that it may enrich this review and support his concepts upon classification, determinants and implications of CL-related stigmata (CLS).

\section{Methods}

This survey was conducted in May 2016, through free discussions with randomly chosen patients with CL who were under treatment and follow-up at the RLCC units in Sana'a and Radaa. Eleven patients (10 females and 1 male) from seven Yemeni governorates were recruited. Only one oral question was directed to all interviewees "How have this disease affected your life?"; without written questionnaires, leading questions or guiding answers, except little words to clarify the type of stigma the patient complained. Variables included patient's number, name, sex, governorate, type of lesions, lesion's/s' location, detected types of stigmata and remarks. Obtained opinions were manually recorded as per their own words, analyzed and tabled.

\section{Results}

Table 1 demonstrates the interviewees' demographic data and the analytical distribution of their answers as per their words over the related variables. Interviewees reported their experience with CLS as the following, seven patients $(63.64 \%)$ experienced social stigma, seven patients $(63.64 \%)$ experienced aesthetic stigma and eight patients $(72.73 \%)$ experienced psychological stigma.

\section{Discussion}

Ten patients (90.91\%) experienced at least one type of CL stigmata, five patients $(45.45 \%)$ experienced the three types of CLS, two patients (18.18\%) experienced two types of CLS, three patients $(27.27 \%)$ experienced one type of CLS, and only one patient hadn't had any experience with CLS.

"She lost herself from all aspects, became dark and sick. But after the successful treatment at RLCC, she improved, attends parties, and her psychological stress was decreased," said a mother of a 17-year-old Yemeni girl with CL small scar on her forehead and complaining of the three types of CLS. "I had a fear from eating or deforming my face and death," said 
www.odermatol.com

Table 1: Interviewees answers' details categorization

\begin{tabular}{|c|c|c|c|c|c|c|c|c|c|c|}
\hline Pt. No. & Pt. name & Sex & Age & Governorate & Lesions & Location & $\begin{array}{l}\text { Social } \\
\text { stigma } \\
\text { CLSS }\end{array}$ & $\begin{array}{l}\text { Aesthetic } \\
\text { stigma } \\
\text { CLAS }\end{array}$ & $\begin{array}{l}\text { Psychological } \\
\text { stigma } \\
\text { CLAS }\end{array}$ & Remarks \\
\hline 1 & Molouk & $\mathrm{F}$ & 39 & Dhamar & $\begin{array}{l}\text { Big } \\
\text { multifocal } \\
\text { MCL } \\
\text { plaque }\end{array}$ & Nose & $\begin{array}{l}\text { Fears of } \\
\text { infecting their } \\
\text { children } \\
\text { Locked into } \\
\text { home } \\
\text { Socially } \\
\text { denied }\end{array}$ & It is ugly & $\begin{array}{l}\text { Depression } \\
\text { Fears of } \\
\text { deformity and } \\
\text { death }\end{array}$ & N/A \\
\hline 2 & Naseem & $\mathrm{F}$ & 19 & Raimah & Big ulcer & Left wrist & No shame & $\begin{array}{l}\text { It is } \\
\text { cosmetically } \\
\text { embarrassing }\end{array}$ & No fairs & $\begin{array}{l}\text { I had not known } \\
\text { what is! }\end{array}$ \\
\hline 3 & Amnah & $\mathrm{F}$ & 40 & Al Baydaa & Big scar & $\begin{array}{l}\text { Left } \\
\text { forearm }\end{array}$ & $\begin{array}{l}\text { Shame } \\
\text { from getting } \\
\text { outside, } \\
\text { joining social } \\
\text { events, or } \\
\text { working in } \\
\text { farm }\end{array}$ & N/A & $\begin{array}{l}\text { Fear of } \\
\text { malignancy }\end{array}$ & $\begin{array}{l}\text { "We shy if it is on } \\
\text { the face Infected } \\
\text { girls usually are } \\
\text { not married, and } \\
\text { refrained from going } \\
\text { to school. Affected } \\
\text { women afraid of } \\
\text { infecting their children } \\
\text { by direct contact } \\
\text { or while showering } \\
\text { them," she said }\end{array}$ \\
\hline 4 & Amar & $\mathrm{F}$ & 15 & $\mathrm{lbb}$ & $\mathrm{DCL}$ & $\begin{array}{l}\text { Cheeks } \\
\text { and left } \\
\text { hand }\end{array}$ & $\begin{array}{l}\text { Always } \\
\text { covers her } \\
\text { face }\end{array}$ & $\begin{array}{l}\text { Always } \\
\text { covers her } \\
\text { face }\end{array}$ & Stress & N/A \\
\hline 5 & Saleh & M & 40 & Al Baydaa & $C L$ & $\begin{array}{l}\text { Left } \\
\text { hand's } \\
\text { dorsum }\end{array}$ & $\begin{array}{l}\text { Feels } \\
\text { forestation }\end{array}$ & It is ugly & Depression & N/A \\
\hline 6 & Tahani & $\mathrm{F}$ & 16 & Mahweet & Ulcer & Upper lip & $\begin{array}{l}\text { Feels shame } \\
\text { Fear of } \\
\text { infecting } \\
\text { others } \\
\text { through food } \\
\text { and drink }\end{array}$ & It is ugly & $\begin{array}{l}\text { Feels something } \\
\text { spreading inside } \\
\text { Fear of getting } \\
\text { disability }\end{array}$ & $\begin{array}{l}\text { "Early and free } \\
\text { medicine fro, RLCC } \\
\text { decreased the } \\
\text { stigma," she said }\end{array}$ \\
\hline 7 & Sondos & $\mathrm{F}$ & 17 & Sana'a & Scar & Forehead & $\begin{array}{l}\text { Friends } \\
\text { were afraid } \\
\text { of being } \\
\text { infected } \\
\text { Home stay } \\
\text { Avoids } \\
\text { all social } \\
\text { activities } \\
\text { Covering } \\
\text { scar with hair } \\
\text { Left work } \\
\text { Became } \\
\text { careful about } \\
\text { study }\end{array}$ & $\begin{array}{l}\text { Unaccepted } \\
\text { look } \\
\text { Carefulness } \\
\text { about others' } \\
\text { opinion } \\
\text { Always asks } \\
\text { her friends } \\
\text { about their } \\
\text { feeling } \\
\text { towards her } \\
\text { affected face }\end{array}$ & $\begin{array}{l}\text { Severe } \\
\text { depression } \\
\text { Aggression } \\
\text { Fair of } \\
\text { malformation }\end{array}$ & $\begin{array}{l}\text { "She lost herself } \\
\text { from all aspects, } \\
\text { became dark, and } \\
\text { sick. After treatment, } \\
\text { she improved, is } \\
\text { attending parties, and } \\
\text { her psychological } \\
\text { stress is decreased," } \\
\text { her mother said }\end{array}$ \\
\hline 8 & Sa'diah & $\mathrm{F}$ & 60 & Al Baydaa & $\mathrm{DCL}$ & $\begin{array}{l}\text { Nose } \\
\text { and left } \\
\text { forearm }\end{array}$ & $\begin{array}{l}\text { Doesn't shy } \\
\text { Usually } \\
\text { attends social } \\
\text { events }\end{array}$ & $\mathrm{N} / \mathrm{A}$ & $\begin{array}{l}\text { Anxiousness } \\
\text { Fear of medical } \\
\text { treatment } \\
\text { (injections) } \\
\text { Fear of disability } \\
\text { and nasal } \\
\text { destruction }\end{array}$ & $\begin{array}{l}\text { "I do not experience } \\
\text { any social or } \\
\text { aesthetic stigma, } \\
\text { because I am old," } \\
\text { she said }\end{array}$ \\
\hline 9 & Rokaiah & $\mathrm{F}$ & 12 & $\mathrm{lbb}$ & Ulcer & Nasal tip & Does not shy & $\mathrm{N} / \mathrm{A}$ & & $\begin{array}{l}\text { "I do not shy, } \\
\text { because it's from } \\
\text { God," she said }\end{array}$ \\
\hline 10 & Mo'agabah & $\mathrm{F}$ & 50 & Hajjah & Plaque & $\begin{array}{l}\text { Nose and } \\
\text { left cheek }\end{array}$ & Does not shy & $\begin{array}{l}\text { Disfigured } \\
\text { face }\end{array}$ & $\begin{array}{l}\text { No anxiety or } \\
\text { depression }\end{array}$ & N/A \\
\hline 11 & Sa'adah & $\mathrm{F}$ & 15 & Al Baydaa & Nodule & Left cheek & $\begin{array}{l}\text { Avoidance } \\
\text { of going out } \\
\text { home } \\
\text { Cover face, } \\
\text { even among } \\
\text { relatives }\end{array}$ & N/A & Fear of deformity & N/A \\
\hline
\end{tabular}


a 39-year-old Yemeni mother with MCL plaque on her nose during a treatment session at the RLCC in Sana'a (Fig. 1). "We shy if it is on the face, infected girls usually do not marry and refrained from going to school, and affected women afraid of infecting their children by direct contact or while showering them," said a 40-year-old woman with a big CL scar on the left forearm. "Early diagnosis and medicine donation through RLCC minimized stigmata that I have," said a 16-year-old girl with upper lip CL ulcer and had the three types of CLS. "I do not experience any social or aesthetic stigma, because I am old," said an elderly woman with DCL and had only CLPS. However, "I do not shy, because it's from the God," said the 12-yearold girl with a small nasal tip CL ulcer who had not experienced any sort of CL-rlated stigmata. All patients who expreseed stigmatization were rural inhabitants while the non-complained girl was an urban inhabitant.

In this survey, interviewees reported variable levels of CL-related social isolation, aesthetic impairment and emotional stress, particularly the girls who would lose their chance of getting married. Interviewees praised the role of the RLCC in alleviating their suffering.

The current survey has supported most of the concepts, implications and determinants introduced in this review in relation to CLS, and concluded that: Yemeni patients and their relatives show challengeable concerns towards CLS as a common complaint which is not only age- or sex-specific, but also depends on many other determinants, such as disease nature, fears, personal and social beliefs. Some patients consider stigmata related to CL worse than the disease itself; Almost, the majority of Yemeni patients with active CL lesions or those carrying CL-related scars and deformities experience at least one type of CL-related stigmata; Psychological type (CLPS) is the most prevalent form of CLS, followed by social (CLSS) and aesthetic (CLAS) types.

\section{DE-STIGMATIZATION}

It is concluded that identifying and resolving its determinants are the two key points to destigmatize CL, or at least decrease the risk of developing serious implications, through: (1) integrating national and community-based programs to combat CL and its related stigmata; (2) early detection and management of CL cases; (3) resolving issues associated with access to antileishmanial drugs; (4) resolving issues associated with women and children who are at the highest risk for
CL stigma; (5) changing the image and misconceptions related to CL as a mysterious disease through education and mass media; (6) physical and social rehabilitation of stigmatized patients; (7) improving economic and general health conditions of the poor.

\section{CONCLUSION}

Apart from its physical impact, it is evident that CL poses severe and spectral stigmata with considerable implications upon the physical, moral, social, economic and public health contexts that may kill stigmatized individuals, both socially and literally.

The author has identified and classified CL related stigmata into three types: (1) CL Social Stigma (CLSS), which might be perceived, enacted or internalized; (2) CL Aesthetic Stigma (CLAS), which might be might be perceived or enacted; (3) CL Psychological Stigma (CLPS). Almost, every patient with CL may has at least one of the three CL-related stigmata.

CLAS is the differential feature that cause stigmatization in CL to look more challengeable, spectral and different from that of all other comparable neglected tropical diseases, such as leprosy. Social and aesthetic stigmata are synonyms of CL in some countries, such as Yemen, and young women are the most affected sex group.

Although, CL is stigmatizing in all affected societies that affects all sex and age groups, the type and severity of CL stigmata vary, however, and rely on several personal, sociopolitical and geopolitical determinant factors that may be common or different across societies.

Available evidence shows that the key point of stigmatization in CL are the characteristic visible active lesions, scars and deformities that predominantly affect exposed, aesthetic parts of the body, in addition to fears and mistaken beliefs about CL nature and transmission methods. Mucosal lesions are more distressing than cutaneous lesions, active lesions than residual scars, DCL more than individual lesions and those on the prominent features more than those on the hidden parts are.

The concurrent survey supports most of the concepts, implications and determinants of CLS introduced in this review. It concluded that the majority of Yemeni patients with active CL lesions or those carrying CL-related scars and deformities experience at least one type of CL-related stigmata considering them worse than the disease itself. Psychological type (CLPS) is 
the most prevalent form of CLS, followed by social (CLSS) and aesthetic (CLAS) types.

Community-led initiatives such as ELYP and RLCC would significantly minimize the extensive impact CL stigmata have on patients' lives.

This report has introduced new ideologies upon stigmatizing process in CL and highlighted further types of CL-related stigmata, which might increase the understanding of that hidden dimension and enrich the global epidemiological profile of CL.

\section{HIGHLIGHTS}

- CL is a spectral and extremely stigmatizing disease that is often compared with leprosy.

- Stigmatization is the hidden and often neglected manifestations of the visible features of CL.

- CL-rlated stigmata has been classified into three main types, social (CLSS), aesthetic (CLAS); and psychological (CLPS).

- CLSS is 'the negative and often unfair beliefs that a society have about patient bearing CL.

- CLAS is 'a sense of a bodily image dissatisfaction'.

- CLPS is 'the deep pain or the psychological stress the infected patient feels as a result of CL-related fears, social stigma and aesthetic stigma'.

- CLPS is the most destructive power in the lives of the affected individuals, particularly women.

- Patients with diffuse or disseminated cutaneous leishmaniasis (DCL) usually suffer stigmata similar to those associated with leprosy.

- The social implication of CLS is much more distressing to patients than the disease individual effects.

- The majority of Yemeni patients with active CL lesions or those carrying CL-related scars and deformities experience at least one type of CLrelated stigmata.

- Yemeni patients with CL often consider CLS worse than the disease itself.

- Stigmata may kill the stigmatized individuals, both socially and literally.

\section{REFERENCES}

1. Van Brakel WH. Measuring health-related stigma--a literature review. Psychol Health Med. 2006;11:307-34.

2. Ramdas, van der Geest $\mathrm{S}$, Henk DFH. Nuancing stigma through ethnography: the case of cutaneous leishmaniasis in Suriname. Social Scien Med. 2016;151:139-46.
3. Tuon FF, Amato Neto V, Sabbaga Amato V. Leishmania: origin, evolution and future since the Precambrian. FEMS Immunol Med Microbiol. 2008;54:158-66.

4. Molly MacMorris-Adix. Leishmaniasis: A review of the disease and the debate over the origin and dispersal of the causaitive parasite Leishmania 2008;1.

5. Al-Kamel MA. Leishmaniasis in Yemen: a clinicoepidemiological study of leishmaniasis in central Yemen. Int J Dermatol. 2016;55:849-55.

6. Émile Durkheim (1982). Rules of Sociological Method 1895; The Free Press. http://comparsociology.com/wp-content/ uploads/2013/02/Emile-Durkheim-Rules-of-SociologicalMethod-1982.pdf [Accessed May 08, 2016.]

7. Goffman E. Stigma: Notes on the management of spoiled identity. Prentice-Hall, Englewood Cliffs (NJ), 1963.

8. Akhoundi M, Kuhls K, Cannet A, Votýpka J, Marty P, Delaunay P, et al. A Historical Overview of the Classification, Evolution and Dispersion of Leishmania Parasites and Sandflies. PLoS Negl Trop Dis. 2016;10:4349.

9. Manson-Bahr PEC. Old World leishmaniasis, p. 206-217. In F. E. G. Cox (ed.), The Wellcome Trust illustrated history of tropical diseases. The Wellcome Trust, 1996, London, United Kingdom.

10. Alrajhi AA, Ibrahim EA, De Vol EB, Khairat M, Faris RM, Maguire JH. Fluconazole for the Treatment of Cutaneous Leishmaniasis Caused by Leishmania major: N Engl J Med. 2002;346:891-5.

11. Camargo LB, Langoni H. Impact of leishmaniasis on public health. J Venom Anim Toxins incl Trop Dis. 2006;12:527-48.

12. WHO. Leishmaniasis Control programme. Report: the consultative meeting on cutaneous leishmaniasis geneva, who headquarters, 2007.

13. Reyburn H, Rowland M, Mohsen M, Khan B, Davies CR. The prolonged epidemic of anthroponotic cutaneous leishmaniasis in Kabul, Afghanistan: "bringing down the neighbourhood. Trans R Soc Trop Med Hyg. 2003;97:170-6.

14. Kassi M, Afghan AK, Rehman R, Kasi PM. Marring Leishmaniasis: The Stigmatization and the Impact of Cutaneous Leishmaniasis in Pakistan and Afghanistan. Utzinger J, ed. PLoS Neglected Tropical Diseases. 2008; 2:259.

15. Al-Kamel MA. Impact of leishmaniasis in women: A practical review with an update on my ISD-supported initiative to combat leishmaniasis in Yemen (ELYP). Int J Women Dermatol. 2016. doi:10.1016/j.ijwd.2016.04.003

16. Weiss MG. Stigma and the Social Burden of Neglected Tropical Diseases. Utzinger J, ed. PLoS Neglected Tropical Diseases. 2008;2:237.

17. Reithinger R, Aadil K, Kolaczinski J, Mohsen M, Hami S. Social impact of leishmaniasis, Afghanistan. Emerg Infect Dis. 2005;11:634-6.

18. Calvopina M, Armijos RX, Hashiguchi Y. Epidemiology of leishmaniasis in Ecuador: current status of knowledge - A review. Mem Inst Oswaldo Cruz. 2004;99:663-72.

19. Diniz JL, Costa MO, Gonçalves DU. Mucocutaneous Leishmaniasis: clinical markers in presumptive diagnosis. Braz J Otorhinolaryngol. 2011;77:380-4.

20. Yanik M, Gurel M, Kati M. The psychological impact of cutaneous leishmaniasis. Clin Exp Dermatol. 2004;29:464-7.

21. Modabber F1, Buffet PA, Torreele E, Milon G, Croft SL. onsultative meeting to develop a strategy for treatment of cutaneous leishmaniasis. Kinetoplastid Biol Dis. 2007;6:3.

22. Homsi Y, Makdisi G. Leishmaniasis: A forgotten disease among neglected people. Internet J Health. 2009;11:1.

23. Odonne G1, Bourdy G, Castillo D, Estevez Y, Lancha-Tangoa A, Alban-Castillo J, et al. Perception of leishmaniasis and evaluation of medicinal plants used by the chayahuita in peru. part II. J Ethnopharmacol. 2009;126:149-58.

24. WHO EMRO. 2016. Malaria and leishmaniasis.

25. Major B, Laurie T. O'Brien. The Social Psychology of Stigma. Ann Rev Psychol. 2005;56:393-421. 


\section{www.odermatol.com}

26. Muela Ribera J, Peeters Grietens K, Toomer E, Hausmann-Muela S. A Word of Caution against the Stigma Trend in Neglected Tropical Disease Research and Control. PLoS Negl Trop Dis. 2009;3:445.

27. Karimkhani C, Wanga V, Coffeng LE, Naghavi P, Dellavalle RP, Naghavi M. Global burden of cutaneous leishmaniasis: a crosssectional analysis from the Global Burden of Disease Study 2013. Lancet Infect Dis. 2016.pii: S1473-3099(16)00003-7.

28. Al-Kamel MA. Spectrum of winter dermatoses in rural Yemen. Int J Dermatol. 2016;55:512-17.
29. Al-Kamel MA. Regional leishmaniasis control center (RLCC) Yemen. in: 22nd Congress of the European Academy of Dermatology and Venereology, Istanbul, Turkey. October 2-6, 2013. EADV Abstracts 2013. - Istanbul: October 02, 2013.

Copyright by Mohamed Ahmed Al-Kamel. This is an open access article distributed under the terms of the Creative Commons Attribution License, which permits unrestricted use, distribution, and reproduction in any medium, provided the original author and source are credited.

Source of Support: Nil, Conflict of Interest: None declared. 